\title{
BMJ Open Epidemiology of paediatric pain-related visits to emergency departments in the USA: a cross-sectional study
}

\author{
Jana L Anderson, ${ }^{1}$ Lucas Oliveira J. e Silva (D) , ${ }^{1}$ Shealeigh A. Funni, ${ }^{2}$ \\ Fernanda Bellolio (D) , ${ }^{1}$ Molly Moore Jeffery (D) ${ }^{2}$
}

To cite: Anderson JL, Oliveira J. e Silva L, Funni SA, et al. Epidemiology of paediatric pain-related visits to emergency departments in the USA: a cross-sectional study. BMJ Open 2021;11:e046497. doi:10.1136/ bmjopen-2020-046497

- Prepublication history and additional supplemental material for this paper are available online. To view these files, please visit the journal online. (http://dx.doi.org/10.1136/ bmjopen-2020-046497)

Received 02 November 2020 Accepted 29 July 2021

Check for updates

(c) Author(s) (or their employer(s)) 2021. Re-use permitted under CC BY-NC. No commercial re-use. See rights and permissions. Published by BMJ.

${ }^{1}$ Department of Emergency Medicine, Mayo Clinic, Rochester, Minnesota, USA

${ }^{2}$ Department of Health Sciences Research, Mayo Clinic, Rochester, Minnesota, USA

Correspondence to Dr Jana L Anderson; anderson.jana@mayo.edu

\section{ABSTRACT}

Objective To describe the epidemiology of paediatric pain-related visits to emergency departments (EDs) across the USA.

Design Cross-sectional study.

Setting A representative sample of US ED visits using data from the National Hospital Ambulatory Medical Care Survey (NHAMCS).

Participants Paediatric (age $\leq 18$ years) ED visits in the 2017 NHAMCS data set.

Data analysis Each visit was coded as pain-related or non-pain-related using the 'reason for visit' variable. Weighted proportions were calculated with $95 \% \mathrm{Cls}$. Logistic regression was used to compare odds of painrelated visits.

Outcome measures Prevalence of pain-related visits among paediatric ED visits.

Results There were an estimated 35 million paediatric ED visits in the USA in 2017, 55.6\% (Cl 53.3\% to 57.8\%) were pain related, which equates to 19.7 million annual visits. The prevalence of pain-related visits reached more than $50 \%$ of visits at age $6-7$ and plateaued at relatively high proportions. Children of races other than white or black had lower odds of having a pain-related visit (OR $0.48, \mathrm{Cl} 0.29$ to 0.81 ) than white children, as did children who were black, though the difference was not statistically significant (OR $0.88, \mathrm{Cl} 0.73$ to 1.06). Relative to children covered by private insurance, children with Medicaid or CHIP (Children's Health Insurance Program) coverage had lower odds of a pain-related visit (OR $0.75, \mathrm{Cl} 0.60$ to 0.93). Injuries represented $46.5 \%$ (Cl $42.0 \%$ to $51.0 \%$ ) of pain-related visits. Pain scores were reported in less than $50 \%$ of pain-related visits.

Conclusion Pain is the reason for visit in $55.6 \%$ of paediatric ED visits across the USA. The prevalence of pain-related visits peak before adolescence and it continues relatively high until the age 18 . Injury, racial disparities in pain and poor pain score reporting should remain major topics of study in the paediatric population.

\section{INTRODUCTION}

Acute pain is known to be one of the most frequent reasons for visiting the emergency department (ED). ${ }^{1}$ Given that pain is a driving factor for the majority of visits, it is important to understand the epidemiology of the disease. There is little up-to-date information

\section{Strengths and limitations of this study}

- This study used data from the National Hospital Ambulatory Medical Care Survey (NHAMCS), which uses a multistage probability design to achieve a representative sample of emergency department visits in the USA.

- We have used up to five 'reason for visit' variables to define the painful nature of visits and to identify pain-related visits.

- Tracking use among individual patients is not possible in the NHAMCS data set.

- The National Center for Health Statistics standardises data collection and processing; however, some inconsistencies may remain across different participating emergency departments.

on paediatric ED visits for acute pain, as the majority of acute pain ED epidemiology studies have excluded children, were limited to one institution, or are now outdated. ${ }^{2-5}$

One of the first paediatric pain ED epidemiology studies was performed in Canada in $1996 .{ }^{3}$ This study used pain scale responses rather than chief complaint to define a painrelated visit. The definition based on pain scale, which is inherently subjective, is frought with unreliability and difficulty with validity in younger children with immature verbal response. Also, some limitations of this study were its short time period of enrolment and the limited setting including only two hospitals and excluding the critical area of the ED. In 2000, the first ED pain study with consecutive enrolment was published. ${ }^{4}$ This study was performed at a single large urban centre and used chief complaint to identify a pain visit. Children were not the focus of this study, but children less than 5 years of age did comprise $14 \%$ of the study population. The first paediatric national level epidemiology study on acute pain in US EDs was performed using data from 1997 to $2000 .{ }^{5}$ This study used the National Hospital Ambulatory Medical Care 
Survey (NHAMCS) database and it used the 'reason for visit' variable to define a pain-related visit. As the last US-based national study on the prevalence of pain-related visits, this data are outdated by two decades. It is unclear if pain remains a major driver of ED visits in the paediatric population.

Our goal in this study was to examine the current prevalence of pain-related visits among children presenting to EDs in the USA. This information will help to build foundational knowledge about the dimension of this clinically important condition and to focus future preventative, home and ED therapy to hopefully decrease the incidence of pain. In addition, this study will provide a background for trends in paediatric pain prevalence looking towards the utilisation and optimisation of analgesics.

\section{METHODS}

\section{Study design, setting and participants}

This was a cross-sectional study of all children (age $\leq 18$ years) in the 2017 NHAMCS, which was released in November of 2019, the latest available at the start of this study. This deidentified data are publicly available from the National Center for Health Statistics (NCHS) and provide a representative sample of ED visits throughout the USA. ${ }^{6}$ We followed the STrengthening the Reporting of OBservational studies in Epidemiology guidelines for reporting observational studies. ${ }^{7}$

\section{Data source}

The NHAMCS ED data set has been collected yearly since 1992 to describe US ED visits and utilisation. ${ }^{8}$ NHAMCS uses extensive surveys in randomly selected sampling units that are then weighted to make national visit-level estimates. The sampling of Emergency Service Areas (ESAs) allows for inclusion of both academic and non-academic institutions. ${ }^{8}$ In the 2017 NHAMCS data set, a total of 479 hospitals were selected of which 374 were in scope and had eligible EDs. Of these, 234 responded, yielding an unweighted ED response rate of $62.6 \%$. This corresponded to a total of 331 ESAs that were identified from the EDs. Of these, 240 responded fully or adequately by providing forms for at least one-half of their expected visits based on the total number of visits during the reporting period. In all, 16709 patient record forms (PRFs) were submitted electronically. The resulting unweighted ESA sample response rate was $72.5 \%$, and the overall unweighted two-stage sampling response rate was $45.4 \%$ ( $48.4 \%$ weighted). The surveys, called PRFs, are obtained by trained individuals from the US Census Bureau. Each ESA is surveyed over a randomly selected 4-week period that rotates each survey year. Subsequently, these surveys are then weighted using population statistics to estimate visits on a national level.

\section{Variables and measurements}

Data were collected through a PRF that can be viewed on the NCHS website. ${ }^{9}$ The PRF lists up to five 'reasons for visit' (RFV), including the first-listed RFV (ie, chief complaint) and up to four additional symptoms, problems or issues. We used these five RFV variables to initially categorise visits as pain-related or non-pain-related.

Codes related to pain were identified by two methods: (1) 'pain' keywords and (2) by physician consensus. First, all RFV codes that contained symptom keywords such as 'pain', 'burn', 'stinging', 'soreness', 'ache' or 'algia' were classified as 'definitely painful'. Second, to classify conditions that did not contain the previously mentioned keywords, two independent physicians, one board-certified in emergency and one board-certified in paediatric emergency medicine, reviewed all of the codes for conditions and classified them as 'definitely painful', 'probably painful' or non-painful. Any disagreements were settled with discussion and consensus. The full list of codes considered as 'definitely painful' or 'probably painful' is detailed in online supplemental data S1.

Pain-related ED visits were defined as any visit with at least one pain-related RFV code (not necessarily the firstlisted RFV code), including those either categorised as 'definitely painful' or 'probably painful'. Pain-related ED visits with a painful chief complaint were defined as any visit in which the first-listed RFV code was a 'definitely painful' condition. This included only those 'definitely painful' conditions or symptoms present at the first-listed $\mathrm{RFV}$, which is the chief complaint of the visit. Pain-related ED visits with injury were defined by the variable 'injury' in the PRF. NHAMCS classifies injury visits as those involving injury, trauma, overdose, poisoning or adverse effects of medical treatments. The original data set does not allow to separate these three categories but rather classifies them under the same umbrella of the 'injury' variable. Visits in which a 'definitely painful' or 'probably painful' code was present and the variable 'injury' was present were considered to be pain-related ED visits with injury.

For pain-related ED visits with a painful chief complaint, we categorised the first-listed RFV code (ie, chief complaint) by body systems including musculoskeletal, abdominal, ear/nose/throat, laceration, headache, general pain, chest, genital-urinary/dysuria, eye, bite, oral and burn-related complaints. The full list of codes and categorisation is detailed in online supplemental data S2.

\section{Data analysis}

Analysis, including the logistic regression model, was completed using the svy suite of tools in Stata V.15, which considers the sampling design of the NHAMCS survey to accurately calculate nationally weighted estimates and their variability (StataCorp LLC, 2017). The total number of paediatric visits, both pain-related and nonpain-related, was estimated. Descriptive statistics were calculated for age, sex, ethnicity, race, geographic region, arrival by emergency medical services, primary payer source, immediacy of visit, injury involvement and pain scale rating. For the variables age, sex, ethnicity and race, 
we used imputed values provided by NHAMCS to reduce the effect of missingness on our results. Children were grouped by age into three developmental stages: age $<6$, age 6-11 and age 12-18 years. Proportions of trauma involvement among pain-related visits and categorisation by body system involved among pain-related visits were also calculated. Weighted proportions were calculated with 95\% CIs. Characteristics between pain-related and non-pain-related visits were compared using t-tests to compare proportions for each baseline characteristic.

ORs and 95\% CI were produced from a multivariable analysis using logistic regression to identify factors associated with pain-related visits. The same variables previously described were included as covariates in the model. We selected variables to include in the model based on theoretical relevance.

\section{Patient and public involvement}

Patients and/or public were not involved in this study.

\section{RESULTS}

We analysed all 4112 paediatric ED visits in the 2017 NHAMCS data set, which represents an estimated 35 million visits during the study period. Across all paediatric ED visits (pain-related and non-pain-related visits), $44.5 \%$ of the children were younger than 6 years of age, $24.1 \%$ aged $6-11$ years and $31.5 \%$ aged $12-18$ years. The cohort was $48.5 \%$ woman. White children made up $67.7 \%$ of the study population, followed by Black children at $28.2 \%$. Hispanic or Latino ethnicity comprised $25.5 \%$ of the cohort. Arrival by ambulance occurred in 5.0\% (95\% CI $4.0 \%$ to $6.1 \%$ ) of all paediatric ED visits (online supplemental data S3).

The prevalence of pain-related ED visits was $55.6 \%$ (95\% CI $53.3 \%$ to $57.8 \%$ ), representing a population estimate of 19.7 million ED visits for paediatric pain. Among all pain-related ED visits, $68.8 \%$ (95\% CI $65.9 \%$ to $71.6 \%)$ had a painful chief complaint. When we plotted the proportion of pain-related ED visits by age, there was a steady increase till the age of 7 and it then plateaued at relatively high proportions, ranging from a minimum of $66.7 \%$ (age 16) to a maximum of $79.0 \%$ (age 12). The pattern remained the same when different definitions of pain-related visits were used (figure 1).

Baseline characteristics between pain-related ED visits and non-pain-related ED visits were generally similar, except for race (non-pain-related visits had a higher proportion of white children than pain-related visits at $70.9 \%$ vs $63.8 \%, \mathrm{p}=0.001$ ), insurance (pain-related visits had a higher proportion of children with private insurance than non-pain-related visits at $26.0 \%$ vs $18.3 \%, \mathrm{p}<0.001$ ) and triage (children triaged as non-urgent were more likely to have a non-pain-related visit at $10.1 \%$ vs $4.5 \%$, $\mathrm{p}<0.001)$. Black children represented similar proportions of pain-related and non-pain-related visits, but painrelated visits had higher proportions of children with races other than Black and White than non-pain-related

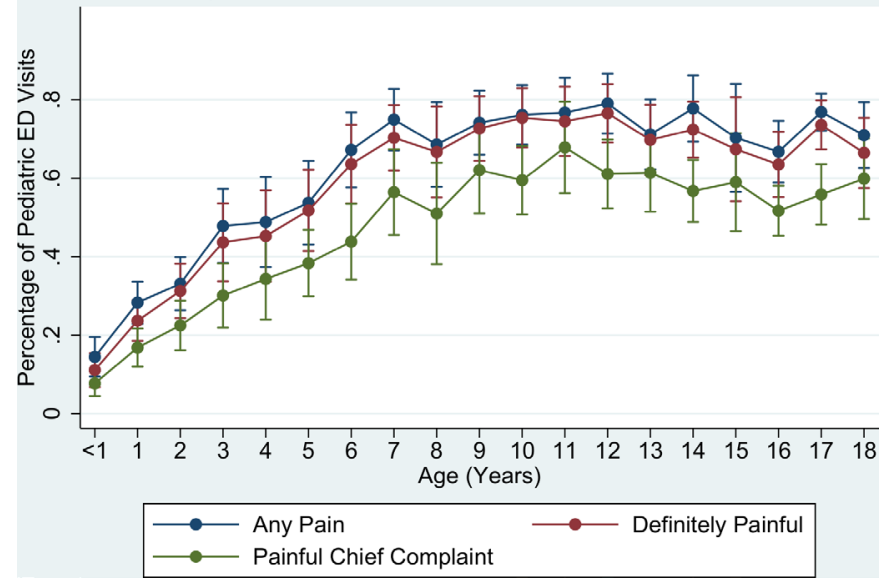

Figure 1 Percentage of pain-related visits by age using different definitions. ED, emergency department.

visits $(5.9 \%$ vs $2.6 \%, \mathrm{p}=0.001)$. There were no significant differences by ethnicity for pain-related and non-painrelated visits. There were no significant differences by sex. As for pain scale reporting among pain-related visits, less than $50 \%$ had pain score available $(14.8 \%$ with a score 0 to 4 and $29.3 \%$ with a score 5 to 10 ) (table 1 ). The same descriptive analysis of baseline characteristics was also performed by comparing visits with 'definitely painful' codes to non-painful visits (online supplemental data S4).

In the multivariable analysis, older age groups (6-11 and $12-18$ years) were significantly more likely to have a painrelated ED visit than the group aged $<6$ years (table 2 ). Race was also found to be an important factor associated with pain-related visits. After adjusting for age and other baseline characteristics, children with races other than Black and White were less likely than White children to have a pain-related ED visit (adjusted OR 0.48, 95\% CI 0.29 to $0.81, \mathrm{p}=0.006$ ). Children with Medicaid were less likely to have a pain-related ED visit than children with private insurance (adjusted OR $0.76,95 \%$ CI 0.60 to 0.93 , $\mathrm{p}=0.008$ ) (table 2).

Injury was reported in $46.5 \%$ (95\% CI $42.0 \%$ to $51.0 \%$ ) or an estimated 9.2 million of the pain-related visits. There were an estimated 1.3 million or $2.5 \%$ of visits with unknown injury involvement.

Among the estimated 13.6 million pain-related ED visits with a painful chief complaint, the body systems most frequently involved were musculoskeletal at $39.9 \%$ (95\% CI $34.6 \%$ to $45.6 \%$ ), followed by abdominal at $16.0 \%$ (95\% CI $11.9 \%$ to $21.1 \%$ ) and ear/nose/throat at $14.8 \%$ (95\% CI $12.1 \%$ to $18.0 \%$ ). In pain-related ED visits without injury, the most common body system involved was abdominal at $32.0 \%$ (95\% CI $25.5 \%$ to $39.3 \%$ ), followed by ear/nose/throat at $31.0 \%$ (95\% CI $23.1 \%$ to $40.2 \%$ ) and headache at $8.8 \%$ (95\% CI $6.6 \%$ to $11.8 \%$ ) (online supplemental data S5). 
Table 1 Baseline characteristic comparison between pain-related and non-pain-related paediatric ED visits

$\begin{array}{ll}\text { Pain-related } & \text { Non-pain-related } \\ \text { ED visit } & \text { ED visit } \\ \mathbf{5 5 . 5 7 \% *} & \mathbf{4 4 . 4 2 \% *} \\ \mathbf{( 5 3 . 2 7 \% , 5 7 . 8 5 \% )} & \mathbf{( 4 2 . 1 5 \% , 4 6 . 7 2 \% )}\end{array}$

Pain-related ED visit

$(53.27 \%, 57.85 \%)$

$44.42 \% \%^{*}$

$(42.15 \%, 46.72 \%)$

P value

\begin{tabular}{|c|c|c|c|}
\hline \multicolumn{4}{|l|}{ Age } \\
\hline$<6$ years & $27.14 \%$ (23.13\%, 31.55\%) & $66.16 \%(61.47 \%, 70.55 \%)$ & $<0.001$ \\
\hline $6-11$ years & $31.58 \%(29.16 \%, 34.10 \%)$ & $14.67 \%(12.71 \%, 16.88 \%)$ & $<0.001$ \\
\hline $12-18$ years & $41.29 \%(36.14 \%, 46.63 \%)$ & $19.17 \%(15.87 \%, 22.96 \%)$ & $<0.001$ \\
\hline \multicolumn{4}{|l|}{ Sex } \\
\hline Female & $48.88 \%(45.36 \%, 52.42 \%)$ & $47.95 \%(45.19 \%, 50.72 \%)$ & 0.732 \\
\hline Male & $51.12 \%(47.58 \%, 54.64 \%)$ & $52.05 \%(49.28 \%, 54.81 \%)$ & 0.732 \\
\hline \multicolumn{4}{|l|}{ Ethnicity } \\
\hline Hispanic or Latino & $25.10 \%(18.09 \%, 33.71 \%)$ & $25.93 \%(19.95 \%, 32.96 \%)$ & 0.714 \\
\hline Not Hispanic or Latino & $74.90 \%(66.29 \%, 81.91 \%)$ & $74.07 \%(67.04 \%, 80.05 \%)$ & 0.714 \\
\hline \multicolumn{4}{|l|}{ Race } \\
\hline White & $63.79 \%(57.54 \%, 69.61 \%)$ & $70.86 \%$ (64.15\%, 76.77\%) & 0.001 \\
\hline Black & $30.27 \%(24.60 \%, 36.61 \%)$ & $26.57 \%(20.89 \%, 33.15 \%)$ & 0.07 \\
\hline Other & $5.94 \%$ (4.32\%, 8.11\%) & $2.56 \%$ (1.72\%, 3.82\%) & 0.001 \\
\hline \multicolumn{4}{|l|}{ Region } \\
\hline Northeast & $12.92 \%(7.84 \%, 20.57 \%)$ & $13.69 \%(8.00 \%, 22.46 \%)$ & 0.592 \\
\hline Midwest & $24.77 \%(17.79 \%, 33.39 \%)$ & $24.63 \%(16.16 \%, 35.66 \%)$ & 0.949 \\
\hline South & $47.02 \%(35.34 \%, 59.04 \%)$ & $43.15 \%(31.00 \%, 56.18 \%)$ & 0.068 \\
\hline West & $15.28 \%(9.21 \%, 24.30 \%)$ & $18.53 \%(10.46 \%, 30.69 \%)$ & 0.123 \\
\hline \multicolumn{4}{|l|}{ Arrived in EMS } \\
\hline Yes & $4.37 \%(3.27 \%, 5.83 \%)$ & $5.67 \%(4.14 \%, 7.72 \%)$ & 0.238 \\
\hline No & $91.13 \%(84.59 \%, 95.06 \%)$ & $89.76 \%(83.06 \%, 94.00 \%)$ & 0.229 \\
\hline Unknown & $3.90 \%(1.01 \%, 13.90 \%)$ & $4.15 \%(1.10 \%, 14.47 \%)$ & 0.412 \\
\hline Blank & $0.59 \%(0.31 \%, 1.13 \%)$ & $0.42 \%(0.19 \%, 0.93 \%)$ & 0.546 \\
\hline \multicolumn{4}{|l|}{ Triage (immediacy) } \\
\hline Immediate & $1.14 \%(0.29 \%, 4.36 \%) \dagger$ & $0.75 \%(0.27 \%, 2.06 \%) \dagger$ & 0.415 \\
\hline Emergent & $6.00 \%(3.73 \%, 9.53 \%)$ & $8.77 \%(5.19 \%, 14.44 \%)$ & 0.02 \\
\hline Urgent & $28.73 \%(22.63 \%, 35.72 \%)$ & $23.87 \%(19.65 \%, 28.66 \%)$ & 0.075 \\
\hline Semi-urgent & $35.07 \%(28.70 \%, 42.02 \%)$ & $31.73 \%(27.04 \%, 36.82 \%)$ & 0.084 \\
\hline Non-urgent & $4.52 \%$ (2.19\%, 9.11\%) & $10.12 \%(6.66 \%, 15.08 \%)$ & $<0.001$ \\
\hline Unknown & $24.53 \%(16.38 \%, 35.04 \%)$ & $24.77 \%(17.01 \%, 34.59 \%)$ & 0.891 \\
\hline \multicolumn{4}{|l|}{ Primary payer } \\
\hline Private insurance & $26.05 \%(21.68 \%, 30.95 \%)$ & $18.29 \%(14.21 \%, 23.22 \%)$ & $<0.001$ \\
\hline Medicare & $0.35 \%(0.17 \%, 0.72 \%) \dagger$ & $0.38 \%(0.16 \%, 0.88 \%) \dagger$ & 0.865 \\
\hline Medicaid or CHIP & $60.91 \%(55.13 \%, 66.39 \%)$ & $65.80 \%(56.93 \%, 73.69 \%)$ & 0.03 \\
\hline Self pay & $4.49 \%(3.11 \%, 6.42 \%)$ & $4.45 \%(2.92 \%, 6.72 \%)$ & 0.961 \\
\hline Worker's compensation & $0.03 \%(0.01 \%, 0.14 \%) \dagger$ & $0.01 \%(0.00 \%, 0.06 \%) \dagger$ & 0.382 \\
\hline No charge/charity & $0.05 \%(0.01 \%, 0.40 \%) \dagger$ & $0.12 \%(0.03 \%, 0.54 \%) \dagger$ & 0.553 \\
\hline Other & $1.36 \%(0.75 \%, 2.47 \%)$ & $1.38 \%(0.72 \%, 2.65 \%)$ & 0.963 \\
\hline Unknown & $5.40 \%(2.31 \%, 12.12 \%)$ & $7.73 \%(2.69 \%, 20.25 \%)$ & 0.216 \\
\hline Blank & $1.36 \%(0.47 \%, 3.92 \%)$ & $1.85 \%(0.63 \%, 5.31 \%)$ & 0.182 \\
\hline \multicolumn{4}{|l|}{ Pain Scale } \\
\hline Blank/unknown & $55.91 \%(46.67 \%, 64.76 \%)$ & $87.46 \%(83.17 \%, 90.78 \%)$ & $<0.001$ \\
\hline 0-4 score & $14.81 \%(11.08 \%, 19.52 \%)$ & $6.44 \%(4.43 \%, 9.27 \%)$ & $<0.001$ \\
\hline
\end{tabular}

Continued 


\begin{tabular}{|c|c|c|c|}
\hline & $\begin{array}{l}\text { Pain-related } \\
\text { ED visit } \\
\mathbf{5 5 . 5 7 \% *} \\
\mathbf{( 5 3 . 2 7 \% , 5 7 . 8 5 \% )}\end{array}$ & $\begin{array}{l}\text { Non-pain-related } \\
\text { ED visit } \\
\mathbf{4 4 . 4 2 \% *} \\
(\mathbf{4 2 . 1 5 \% , 4 6 . 7 2 \% )}\end{array}$ & $P$ value \\
\hline
\end{tabular}

CHIP (Children's Health Insurance Program)

${ }^{*}$ Results are presented as weighted proportions with its $95 \% \mathrm{Cls}$.

†This represented cell sizes smaller than 30 , which are considered not reliable for meaningful analysis by the NHAMCS guidelines.

ED, emergency department; EMS, emergency medical service; NHAMCS, National Hospital Ambulatory Medical Care Survey.

\section{DISCUSSION}

In this cross-sectional study, we found that $55.6 \%$ of all US ED paediatric visits were related to pain. This equates to 19.7 million yearly visits to EDs across the US for paediatric pain. The prevalence of pain-related visits in children peaked as early as 7 years old and it then plateaued at relatively high proportions. Race and payer type yielded important differences in the likelihood of a pain-related ED visit. Children of races other than Black and White had significantly more painful than non-painful visits, while white children had significantly more non-painful than painful visits. However, when compared with white race, children of races other than Black and white were less likely to have a pain-related visit in the multivariable analysis. Also, children with Medicaid were less likely to have a pain-related visit than children with private insurance. An injury was involved in just under half of pain-related ED visits in the paediatric population. Finally, recording of pain scores remains poor among painful visits.

Few NHAMCS studies have assessed the prevalence of pain-related ED visits in the paediatric population. In a study looking at paediatric ED visits from the NHAMCS 1997-2000 survey data set, Drendel et al reported that $51.7 \%$ of all paediatric ED visits had a painful reason for visit, with an approximated estimate of 10.3 million visits for pain during the 4-year study period. ${ }^{5}$ The prevalence of painful ED visits has remained relatively stable (now $55.6 \%$ ), but the total number of painful paediatric ED visits has grown substantially, now reaching an estimated 19.7 million during a 1-year period. Also, these data indicate that acute pain remains highly prevalent among the several reasons for which children present to the ED. This pattern is similar to the adult literature, where painrelated ED visits remained consistently high between $42 \%$ and $45 \%$ of $\mathrm{ED}$ visits. ${ }^{2} 10$

Our study shows that the prevalence of pain-related ED visits significantly increases from infancy till age 7 , reaching a relatively high proportion that then remains similar throughout childhood and adolescence. This is the first study to show that the proportion of pain-related ED visits is similar for children from 7 to 12 years as to the typical adolescent, 13 to 18 years. This data emphasise the need for primary injury prevention in young children. The type and effectiveness of prevention interventions, however, will depend on factors such as child's age, level of development and household environment. ${ }^{11}$

As expected, injuries (which includes trauma in the NHAMCS definition) remain a major source of painrelated ED visits during childhood. Just under half of all paediatric pain-related ED visits involved an injury, once again emphasising the importance of more prevention initiatives. These findings are similar to older studies using the NHAMCS data set, ${ }^{5}$ indicating little change in the proportion of paediatric pain-related ED visits due to injuries in the last 20 years.

When comparing baseline characteristics between painrelated and non-pain-related paediatric ED visits, there were significant differences in race. Pain-related visits had significantly higher proportions of children who were of races other than Black or White than non-pain-related visits. This category is comprised of American Indian or Alaskan native, Asian, Native Hawaiian or Other Pacific Islander. This group is small and comprises only $4 \%$ of the total study population but is still important given their large difference in pain to non-pain visits. Studies on adults have shown that American Indian and Alaskan native populations do have a higher rate of pain symptoms and pain conditions compared with the general US population. ${ }^{12}$ Also, Native American adolescents were noted to have the highest rate of all the race/ethnicity groups for any substance abuse and opioid abuse ${ }^{13}$ Despite having more painful than non-painful visits, this group was less likely to have a pain-related ED visit than the group of White children in the multivariable analysis. Nevertheless, studies have shown that minoritised groups are at particularly high risk of receiving inadequate pain treatment. ${ }^{101415}$ White children, for example, are more likely to receive opioid prescriptions than non-white children. ${ }^{16}$ Given these known disparities in pain management, the findings of our study should emphasise the importance of assessing and treating pain in minoritised children seen in the ED.

The pain scale was blank or unknown in more than half of paediatric pain-related ED visits. This is similar to the percentage of pain scores documented in the study by Drendel et al looking at 1997-2000 data from NHAMCS, ${ }^{5}$ highlighting that pain score recording is poorly performed in children and has not improved over the 
Table 2 Multivariable logistic regression analysis of the association between baseline characteristics and the outcome of a pain-related visit

\begin{tabular}{|c|c|c|}
\hline \multicolumn{3}{|l|}{ Age } \\
\hline$<6$ years & Reference & \\
\hline $6-11$ years & 5.21 (4.14 to 6.55$)$ & $<0.001$ \\
\hline $12-18$ years & 5.25 (4.23 to 6.52$)$ & $<0.001$ \\
\hline \multicolumn{3}{|l|}{ Sex } \\
\hline Female & Reference & \\
\hline Male & 1.1 (0.89 to 1.39$)$ & 0.344 \\
\hline \multicolumn{3}{|l|}{ Ethnicity } \\
\hline Hispanic or Latino & Reference & \\
\hline Not Hispanic or Latino & 1.05 (0.87 to 1.25$)$ & 0.629 \\
\hline \multicolumn{3}{|l|}{ Race } \\
\hline White & Reference & \\
\hline Black & 0.88 (0.73 to 1.06$)$ & 0.186 \\
\hline Other & 0.48 (0.29 to 0.81$)$ & 0.006 \\
\hline \multicolumn{3}{|l|}{ Region } \\
\hline Northeast & Reference & \\
\hline Midwest & 0.98 (0.73 to 1.32$)$ & 0.907 \\
\hline South & 0.95 (0.71 to 1.27$)$ & 0.716 \\
\hline West & $0.88(0.67$ to 1.16$)$ & 0.352 \\
\hline \multicolumn{3}{|l|}{ Arrived in EMS } \\
\hline Yes & Reference & \\
\hline No & 1.48 (0.91 to 2.43$)$ & 0.116 \\
\hline Blank/unknown & $1.58(0.90$ to 2.75$)$ & 0.108 \\
\hline \multicolumn{3}{|l|}{ Triage (immediacy) } \\
\hline No triage for visit, but ESA & 1.06 (0.40 to 2.83$)$ & 0.876 \\
\hline Immediate & $0.91(0.20,4.21)$ & 0.870 \\
\hline Emergent & 1.99 (1.14 to 3.48$)$ & 0.002 \\
\hline Urgent & Reference & \\
\hline Semi-urgent & 0.95 (0.71 to 1.27$)$ & 0.649 \\
\hline Non-urgent & 2.20 (1.15 to 4.18$)$ & 0.002 \\
\hline Blank/unknown & $1.03(0.73$ to 1.44$)$ & 0.844 \\
\hline \multicolumn{3}{|l|}{ Primary payer } \\
\hline Private insurance & Reference & \\
\hline Medicare & $1.10(0.29$ to 4.21$)$ & 0.883 \\
\hline Medicaid or CHIP & 0.75 (0.60 to 0.93$)$ & 0.008 \\
\hline Self pay & $0.76(0.50$ to 1.16$)$ & 0.200 \\
\hline Worker's compensation & 2.04 (0.30 to 13.95$)$ & 0.462 \\
\hline No charge/charity & 0.45 (0.08 to 2.56$)$ & 0.363 \\
\hline Other & 0.74 (0.29 to 1.87$)$ & 0.515 \\
\hline Blank/unknown & 0.55 (0.38 to 0.79$)$ & 0.002 \\
\hline
\end{tabular}

CHIP (Children's Health Insurance Program)

EMS, emergency medical service; ESA, Emergency Service Area.

last two decades. Further examination will be necessary to evaluate whether this missing data refer to poor reporting or to the difficulty of using structured pain scales in children, especially in younger groups with immature verbal response. The poor reporting of pain scores also occurs in adult populations. ${ }^{17}$ For this reason, one may argue that the difficulty of using pain scales in children does not play a major role on the absence of these data in the NHAMCS surveys.

\section{LIMITATIONS}

Our study had several limitations. First, the proportion of pain-related visits in the youngest children (age $<6$ years) may be underestimated. This group is prone to misclassification due to their immature verbal response. Certain presentations such as fever or irritability, for example, may have been equivocally categorised as non-pain related even though these may represent pain-related visits. Second, our classification system for visits does not rely on the reported pain score. There are two main reasons behind this decision: (1) as previously noted, many children may be unable to respond to the standard pain score question, making it less useful for a large portion of our population and (2) the pain score field in NHAMCS has a large proportion of missing data. For these reasons, we used clinical knowledge to classify RFVs according to how painful they are likely to be. Because children classified as having painful visits are nearly five times as likely to report a pain score of 6 or higher and 3.5 times as likely to have a recorded pain score, we believe that the pain classification we created is appropriate for use. Third, NHAMCS is a cross-sectional survey, and tracking use among individual patients is not possible. Fourth, NHAMCS may include errors in documentation and missing data. Although NCHS standardises data collection and processing, some inconsistencies may remain across different participating EDs. Finally, these data may be only representative of US paediatric ED visits. ${ }^{8}$

\section{CONCLUSIONS}

This study provides the most current prevalence of paediatric pain-related visits to EDs across the USA at $55.6 \%$. The prevalence of pain-related visit peaks before the adolescence and it persists relatively high. Younger children should receive as much attention to injury and pain prevention as older children. Injuries, racial disparities and poor pain score reporting should remain major topics of research in the care of paediatric acute pain in the ED.

Twitter Lucas Oliveira J. e Silva @lucasojesilva12, Fernanda Bellolio @mfbellolio and Molly Moore Jeffery @mollyjeffery

Contributors Conceptualisation: JLA, FB and MMJ. Formal analysis: SAF and MMJ. Investigation: JLA, LOJS, FB, MMJ. Methodology: LOJS, FB, MMJ. Project administration: JLA. Supervision: MMJ. Validation: FB and MMJ. Writing—original draft: JLA. Writing — review and editing: JLA, LOJS, SAF, FB, MMJ. Guarantor: JLA MMJ. All authors provided critical revision and contribution for important intellectual content.

Funding This study received funding through the James $\mathrm{H}$. and Helen $\mathrm{F}$. Crossingham Emergency Medicine Career Development Award (TN005446; Principal Investigator: Jana L Anderson MD). The funders' and authors' institutions are not responsible for its content.

Competing interests None declared. 
Patient consent for publication Not required.

Ethics approval NHAMCS is approved by the Ethics Review Board of the National Center for Health Statistics (NCHS), a division of the Center for Disease Control and Prevention (CDC). ${ }^{6}$ Because this study used pre-existing, de-identified data, the Institutional Review Board deemed this study exempt.

Provenance and peer review Not commissioned; externally peer reviewed.

Data availability statement Data are available in a public, open access repository. The NHAMCS data are publicly available at https://www.cdc.gov/nchs/ahcd/ datasets_documentation_related.htm.

Supplemental material This content has been supplied by the author(s). It has not been vetted by BMJ Publishing Group Limited (BMJ) and may not have been peer-reviewed. Any opinions or recommendations discussed are solely those of the author(s) and are not endorsed by BMJ. BMJ disclaims all liability and responsibility arising from any reliance placed on the content. Where the content includes any translated material, BMJ does not warrant the accuracy and reliability of the translations (including but not limited to local regulations, clinical guidelines, terminology, drug names and drug dosages), and is not responsible for any error and/or omissions arising from translation and adaptation or otherwise.

Open access This is an open access article distributed in accordance with the Creative Commons Attribution Non Commercial (CC BY-NC 4.0) license, which permits others to distribute, remix, adapt, build upon this work non-commercially, and license their derivative works on different terms, provided the original work is properly cited, appropriate credit is given, any changes made indicated, and the use is non-commercial. See: http://creativecommons.org/licenses/by-nc/4.0/.

\section{ORCID IDs}

Lucas Oliveira J. e Silva http://orcid.org/0000-0001-5388-9163

Fernanda Bellolio http://orcid.org/0000-0002-1632-4750

Molly Moore Jeffery http://orcid.org/0000-0003-3854-6810

\section{REFERENCES}

1 Krauss BS, Calligaris L, Green SM, et al. Current concepts in management of pain in children in the emergency department. Lancet 2016;387:83-92.

2 Chang $\mathrm{H}-\mathrm{Y}$, Daubresse M, Kruszewski SP, et al. Prevalence and treatment of pain in EDs in the United States, 2000 to 2010. Am J Emerg Med 2014;32:421-31.
3 Johnston CC, Gagnon AJ, Fullerton L, et al. One-Week survey of pain intensity on admission to and discharge from the emergency department: a pilot study. J Emerg Med 1998;16:377-82.

4 Cordell WH, Keene KK, Giles BK, et al. The high prevalence of pain in emergency medical care. Am J Emerg Med 2002;20:165-9.

5 Drendel AL, Brousseau DC, Gorelick MH. Pain assessment for pediatric patients in the emergency department. Pediatrics 2006;117:1511-8.

6 CDC. National center for health statistics. Available: https://www. cdc.gov/nchs/ahcd/index.htm [Accessed 10 Jul 2019].

7 Vandenbroucke JP, von Elm E, Altman DG, et al. Strengthening the reporting of observational studies in epidemiology (STROBE): explanation and elaboration. Int J Surg 2014;12:1500-24.

8 McCaig LF, Burt CW. Understanding and interpreting the National Hospital ambulatory medical care survey: key questions and answers. Ann Emerg Med 2012;60:716-21.

9 Center for Health Statistics N. 2017 national ambulatory medical care survey patient record form sample card 2017.

10 Pletcher MJ, Kertesz SG, Kohn MA, et al. Trends in opioid prescribing by race/ethnicity for patients seeking care in US emergency departments. JAMA 2008;299:70-8.

11 Barcelos RS, Del-Ponte B, Santos IS. Interventions to reduce accidents in childhood: a systematic review. J Pediatr 2018;94:351-67.

12 Jimenez N, Garroutte E, Kundu A, et al. A review of the experience, epidemiology, and management of pain among American Indian, Alaska native, and Aboriginal Canadian peoples. J Pain 2011;12:511-22.

13 Wu L-T, Woody GE, Yang C, et al. Racial/Ethnic variations in substance-related disorders among adolescents in the United States. Arch Gen Psychiatry 2011;68:1176-85.

14 Todd KH, Samaroo N, Hoffman JR. Ethnicity as a risk factor for inadequate emergency department analgesia. JAMA 1993;269:1537-9.

15 Todd KH, Deaton C, D'Adamo AP, et al. Ethnicity and analgesic practice. Ann Emerg Med 2000;35:11-16.

16 Tomaszewski DM, Arbuckle C, Yang S, et al. Trends in opioid use in pediatric patients in US emergency departments from 2006 to 2015. JAMA Netw Open 2018;1:e186161.

17 Hoppe JA, Nelson LS, Perrone J, et al. Opioid prescribing in a cross section of US emergency departments. Ann Emerg Med 2015;66:253-9. 